\title{
The Impact on the Environment and Economy Due to the Introduction of Electric Cars: Based on the Fuzzy Synthetical Evaluation Method
}

\author{
Heli Gao \\ Department of Mathematics, Binzhou University, Binzhou, China \\ Email: gaoheli81@163.com
}

How to cite this paper: Gao, H.L. (2016) The Impact on the Environment and Economy Due to the Introduction of Electric Cars: Based on the Fuzzy Synthetical Evaluation Method. Journal of Applied Mathematics and Physics, 4, 2172-2185. http://dx.doi.org/10.4236/jamp.2016.412212

Received: November 15, 2016 Accepted: December 16, 2016 Published: December 19, 2016

Copyright $\odot 2016$ by author and Scientific Research Publishing Inc. This work is licensed under the Creative Commons Attribution International License (CC BY 4.0).

http://creativecommons.org/licenses/by/4.0/

\begin{abstract}
In this paper, we establish a model to analyze the influence of widespread use of electric vehicle on environment, society and economist based on Fuzzy Comprehensive Evaluation method. We set the fuzzy objects are internal combustion engine vehicles, pure electric vehicles and hybrid electric vehicles. Considering the difference of environment, society and economics, we use of three different kinds to define the fuzzy evaluation factor sets. According to the data and calculating results, we finally obtain fuzzy synthetical evaluation matrix. Through comparing and analysis, we draw such conclusion that the widespread using of electric vehicle is benefit for both environment and economics, while has disadvantageous influence for some aspects on society. In Section 3, we establish a model to estimate the influence of widespread use of electric vehicles on energy saving. According to the proportion of coal resources in the whole energies, we use Linear Regression Model to forecast the development situation in the following several years. Contrasting energy consumptions of electric vehicles and internal combustion engine vehicles, we calculate the whole energies saved by widespread use of electric vehicles. In Section 4, we establish a multiobjective programming model to plan the number and type of power station. Considering the thermal power, hydropower, nuclear power and solar power as four ways, combined with the funds of setting up power station, running funds and the cost of dealing with the pollutants, we find the objective function and four constraints, and finally we reach optimal solution using lingo software.
\end{abstract}

\section{Keywords}

Electric Vehicle, Fuzzy Comprehensive Evaluation, Linear Regression Model, Multi-Objective Programming Model 


\section{Introduction}

Electric vehicles have been identified as being a key technology in reducing future emissions and energy consumption in the mobility sector. The focus of this article is to review and assess the energy efficiency and the environmental impact of battery electric cars, which is the only technical alternative on the market available today to vehicles with internal combustion engine.

\section{Environmental and Economic Effects of Widespread Introduction of Electric Vehicles}

In this section, we analysis the influence of the widespread use of electric vehicles on the respects of environment, society, economics and human health etc. based on Fuzzy Synthetical Evaluation.

\subsection{Fuzzy Synthetical Evaluation Method}

Assume that the object set of fuzzy evaluation is

$$
X=\left\{x_{i}\right\}, i=1,2, \cdots,
$$

and the factor set of fuzzy evaluation is

$$
Y=\left\{y_{j}\right\}, j=1,2, \cdots .
$$

The key problem using fuzzy synthetical evaluation method is to set the grade function of membership and find the degree of membership.

In this paper, membership grades have two kinds. We use partial large membership function and partial small membership function respectively to find these two kinds membership grades.

The greater the factor $y_{j}$ is, the better the performance of evaluation object, so the membership function is an increasing function of $y_{j}$, which we call partial large membership function. On the contrary, the greater the factor $y_{j}$ is, the poorer the performance of evaluation object, so the membership function is an decreasing function of $y_{j}$, which we call partial small membership function.

In this paper we use the partial small membership function, which are defined as following:

$$
\gamma_{j i}=\left[\frac{\max \left(y_{j}\right)-y_{j}\left(x_{i}\right)}{\max \left(y_{j}\right)-\min \left(y_{j}\right)}\right] .
$$

The single-factor evaluation matrix is

$$
R=\left[\begin{array}{cccc}
r_{11} & r_{12} & \ldots & r_{1 m} \\
r_{21} & r_{22} & \ldots & r_{2 m} \\
\ldots & \ldots & \ldots & \ldots \\
r_{n 1} & r_{n 2} & \ldots & r_{n m}
\end{array}\right]=\left[r_{j i}\right]_{n \times m}
$$

After we obtain the evaluation matrix, we need determine variable factors' weights in the factor sets. In many cases, these weights are known. Even we don't know, we can 
obtained these weights through certain methods, commonly used methods are the standard deviation, expert Scoring, etc..

In the following, we give the definition of the standard deviation method.

$$
w_{i}=\frac{\sigma_{i}}{\sum_{i=1}^{n} \sigma_{i}},
$$

where, $\sigma_{i}$ is the standard deviation of $i$ rd line element of single-factor evaluation matrix $R$.

Expert scoring method is a relatively reasonable method in this problem. It takes into account the comprehensive factors to draw a reasonable value. But no matter which method we used, we should satisfy the condition that $\sum w_{i}=1$.

Through calculation, we can obtain the weights, and define the matrix of weight as

$$
A=\left[w_{1}, w_{2}, w_{3} \ldots\right] \text {. }
$$

The final and most critical step is to evaluate comprehensively. The comprehensive evaluation matrix is

$$
C=A \cdot R=\left[c_{1}, c_{2}, \cdots, c_{n}\right],
$$

in which $C$ represents the comprehensive evaluation matrix of fuzzy evaluation object sets, and $c_{i}(i=1, \cdots, n)$ is the comprehensive evaluation value of fuzzy evaluation object $x_{i}(i=1, \cdots, n)$, the biggest value after evaluation is the one we want to select.

\subsection{Data Analysis}

When we use the fuzzy synthetical evaluation method to evaluate the influence of electric vehicles on environment., the fuzzy objects $X=\left\{x_{i}\right\}, i=1,2,3$ represents the vehicles using fossil fuels, pure electric vehicles and hybrid electric vehicles respectively, and fuzzy objects $Y=\left\{y_{j}\right\}, j=1,2,3,4$ represents $\mathrm{CO}, \mathrm{NO}_{\mathrm{n}}, \mathrm{SO}_{2}$ and $\mathrm{CO}_{2}$.

First of all, we need to calculate the pollution on environment of electric vehicles and fossil fuel vehicles. An electric car depends on the fuel mix at the power plants in the country in which they are driven. How green they are depends on the fuel mix at the power plants in the country in which they are driven. An electric car in Britain today, for instance, produces around $20 \%$ less in $\mathrm{CO}_{2}$ emissions than a car with a petrol engine [1].

In the following, we first calculate the proportion of energy required to produce electricity in United States. The following figure shows the energy and power structure in US [2].

In Figure 1, we can see that $18 \%$ of the energy in the United States came from natural gas, $48 \%$ came from coal, and $1 \%$ came from oil. While the main pollutants produced in power generation derived from coal and Natural gas combustion. We already know that electric vehicles need $15 \mathrm{kwh}$ electricity power per 100 kilometers, $2.7 \mathrm{kwh}$ of which obtained from combustion of Natural gas while $7.2 \mathrm{kwh}$ through combustion of coal.

We know by querying the Wikipedia [3], an EV recharged from the existing US grid electricity emits about 115 grams of $\mathrm{CO}_{2}$ per kilometer driven $\left(6.5 \mathrm{oz}\left(\mathrm{CO}_{2}\right) / \mathrm{mi}\right)$, whe- 
reas a conventional US-market gasoline powered car emits $250 \mathrm{~g}\left(\mathrm{CO}_{2}\right) / \mathrm{km}(14 \mathrm{oZ}$ $\left(\left(\mathrm{CO}_{2}\right) / \mathrm{mi}\right)$ (most from its tailpipe, some from the production and distribution of gasoline). The savings are questionable relative to hybrid or diesel cars, (according to official British government testing, the most efficient European market cars are well below 115 grams of $\mathrm{CO}_{2}$ per kilometer driven, although a study in Scotland gave $149.5 \mathrm{~g}$ $\mathrm{CO}_{2} / \mathrm{km}$ as the average for new cars in the UK), but would be more significant in countries with cleaner electric infrastructure. In a worst case scenario where incremental electricity demand would be met exclusively with coal, a 2009 study conducted by the World Wide Fund for Nature and IZES found that a mid-size EV would emit roughly $200 \mathrm{~g}\left(\mathrm{CO}_{2}\right) / \mathrm{km}\left(11 \mathrm{oz}\left(\mathrm{CO}_{2}\right) / \mathrm{mi}\right)$, compared with an average of $170 \mathrm{~g}\left(\mathrm{CO}_{2}\right) / \mathrm{km}(9.7 \mathrm{oZ}$ $\left.\left(\mathrm{CO}_{2}\right) / \mathrm{mi}\right)$ for a gasoline powered compact car.

After considering the proportion of internal combustion engine vehicles and electric vehicles in United States, we obtained Table 1 as following.

In determining the impacts of these four pollutants weight, Greenhouse effect is now considered more serious diesel locomotive we should set to be the maximum. Combined with the actual condition and the relevant literature and materials, we set the weight as following:

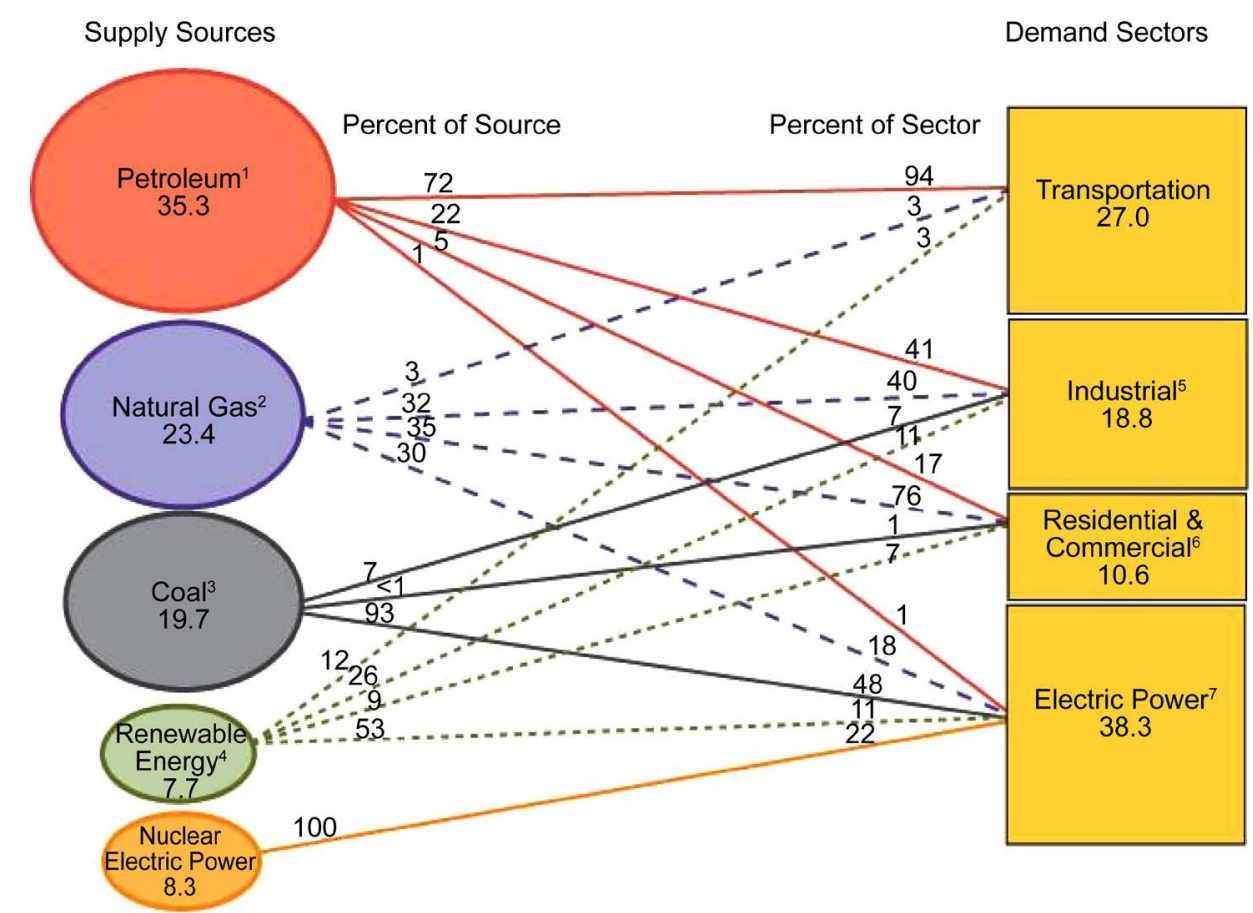

Figure 1. US primary energy consumption by source and sector, 2009.

Table 1. Emissions of greenhouse gases per kilometer by different types of vehicle.

\begin{tabular}{ccccc}
\hline Vehicle type & $\mathrm{CO}(\mathrm{g})$ & $\mathrm{NO}_{\mathrm{n}}(\mathrm{g})$ & $\mathrm{SO}_{2}(\mathrm{~g})$ & $\mathrm{CO}_{2}(\mathrm{~g})$ \\
\hline Pure electric vehicles & 2.9 & 19.6 & 72 & 115 \\
Hybrid & 2.5 & 51.3 & 86 & 163 \\
Diesel locomotive & 2.3 & 70.5 & 166 & 170 \\
\hline
\end{tabular}




$$
B=\left[\begin{array}{llll}
0.2 & 0.2 & 0.2 & 0.4
\end{array}\right]
$$

But, the pollution caused by the increasing need to dispose of increasing number of large batteries effect is also great. According to the data we obtained, the used batteries can damage human health and environment greatly. For instance, a small button battery can pollute 600 cubic meters of water. Even a fully standards-compliant low mercury battery (refer to the weight of mercury content of less than $0.025 \%$ of the battery cell), if it is thrown into a cubic meter water, it will make the mercury content of water exceeds the standard 25 times. Considering the widespread using of electric vehicle, government should consider the dispose of used batteries considerably.

\subsection{The Evaluation of Influence on Society by Widely Using Electric Vehicles}

When discussing the influence on society, we need to consider the influence generated by widely using electric vehicles. In this issue, we consider the main index is how convenient the electric vehicle can cause, including the maximum speed VE can reach and how long distance it can reach once time.

We obtained the following data from Wikipedia [4]:

Table 2 shows top speeds and nominal ranges of several brands of electric cars, from which we can calculate the average top speed and maximum driving distance of pure electric vehicles. Once more, considering general data of the internal combustion engine vehicles, we compare the electric vehicle and internal combustion engine vehicles on two aspects as following table.

In this section, we select these two kinds of vehicles which in Table 3 as the fuzzy evaluation objects, using $X=\left\{x_{i}\right\}, i=1,2$ represent electric vehicle and internal combustion engine vehicles respectively. $Y=\left\{y_{j}\right\}, j=1,2$ represent the maximum speed and longest drive distance.

Since the maximum speed and long range distance is benefit to consumer, we use partial large membership function here, through substitute data to we can obtain the membership matrix

Table 2. Road cars with a top speed above $105 \mathrm{~km} / \mathrm{h}$ (65 mph).

\begin{tabular}{ccc}
\hline Model & Top Speed & Nominal Range \\
\hline BEV, "Electron" & $110 \mathrm{~km} / \mathrm{h}(68 \mathrm{mph})$ & $120 \mathrm{~km}(75 \mathrm{mi})$ \\
Citroën C-Zero & $130 \mathrm{~km} / \mathrm{h}(81 \mathrm{mph})$ & $150 \mathrm{~km}(93 \mathrm{mi})$ \\
Ford Focus Electric & $135 \mathrm{~km} / \mathrm{h}(84 \mathrm{mph})$ & $122 \mathrm{~km}(76 \mathrm{mi})$ \\
Mia Electric & $100 \mathrm{~km} / \mathrm{h}(62 \mathrm{mph})$ & $125 \mathrm{~km}(78 \mathrm{mi})$ \\
Mitsubishi i-MiEV & $130 \mathrm{~km} / \mathrm{h}(81 \mathrm{mph})$ & $170 \mathrm{~km}(106 \mathrm{mi})$ \\
Nissan Leaf & $150 \mathrm{~km} / \mathrm{h}(93 \mathrm{mph})$ & EPA rating $117 \mathrm{~km}(73 \mathrm{mi})$ \\
Renault Fluence ZE & $135 \mathrm{~km} / \mathrm{h}(84 \mathrm{mph})$, & $135 \mathrm{~km}(84 \mathrm{mi})+15 \mathrm{~km}$ \\
Smart ED & electronically limited & 1 limp home mode \\
\hline
\end{tabular}




$$
R=\left[\begin{array}{ll}
0 & 1 \\
0 & 1
\end{array}\right] .
$$

when considering the weights of maximum speed and the maximum range distance, we set these weights maximum and considering the actual condition, we define that

$$
B=\left[\begin{array}{ll}
0.4 & 0.6
\end{array}\right] \text {. }
$$

Through substituting the evaluation matrix and weight coefficient into Equation (4), we obtain that

$$
C=B \cdot R=\left[\begin{array}{ll}
0 & 1
\end{array}\right] .
$$

We can see that we should consider the necessity of setting up the recharge station. Government should take into account these stations reasonably, since the longest range distance is $160 \mathrm{~km}$ on average, we should consider the reasonable arrangement of these stations, for instance, $100 \mathrm{~km}$ a station.

\subsection{The Evaluation of Influence on Economic by Widespread Using Electric Vehicle}

Can we save money by widely using electric vehicles? Now we are considering this problem through the cost of driving a vehicle car.

Below is the table of the first mass-market electric cars are now arriving in showrooms in America, Europe and Japan. They come in three flavors. Pure electric vehicles like Nissan's Leaf can be driven for $150 \mathrm{~km}$ or so before they need to be recharged for six to eight hours. Range-extenders like GM's Volt are powered by an electric motor that can be recharged either from the mains or by an on-board internalcombustion engine. Then there are familiar hybrids like the Toyota Prius, now being adapted to take a charging cord and with a longer electric-only range.

By simple calculation of the data in Table 4, and by finding the relevant data of a Fuel vehicles, we have Table 5 as following.

Table 3. Maximum speed and driving distance by different types of vehicle.

\begin{tabular}{ccc}
\hline Vehicle type & Top speed & Maximum driving distance \\
\hline Pure electric vehicles & 120 & 132 \\
Diesel locomotive & 130 & 300 \\
\hline
\end{tabular}

Table 4. Claimed electric-only range of different brands of electric vehicles.

\begin{tabular}{ccc}
\hline Electric car & Technology & Claimed electric-only range, km \\
\hline Mitsubishii-MIEV & Battery & 160 \\
Nissan Leaf & Battery & 160 \\
GM Chevrolet Volt/Ampera & Battery/range extender & 64 \\
Renault Fluence & Battery & 160 \\
Toyota Prius Plug-in & Hybird & 20 \\
\hline
\end{tabular}

Sources: Company reports; The Economist. 
Table 5. Costsbydifferent types of vehicle.

\begin{tabular}{ccc}
\hline Vehicle type & cost of manufacture (million) & $100 \mathrm{~km}$ cost (dols.) \\
\hline Electric cars & 2.3 & 7.6 \\
Fuel vehicles & 1 & 15.3 \\
\hline
\end{tabular}

Because the more spending is not conducive to the economy, so we use partial small membership function. By the data in Table 5, letting $x_{1}=2.3, x_{2}=1$ and $y_{1}=7.6$, $y_{2}=15.3$ in Equation (1), we calculated the membership matrix:

$$
R=\left[\begin{array}{ll}
0 & 1 \\
1 & 0
\end{array}\right]
$$

In determining the weight of cost and time spent, in view of the rising price of oil pollution of the environment and various social factors, so the cost per hundred kilometers weight should be as large as possible, the weight as:

$$
B=\left[\begin{array}{ll}
0.2 & 0.8
\end{array}\right] \text {. }
$$

Through the evaluation of matrix and the weight coefficients into Equation (4) were:

$$
C=B \cdot R=\left[\begin{array}{ll}
0.8 & 0.2
\end{array}\right] \text {. }
$$

Through the model concluded that the use of electric vehicles in the process is more economical, the use of small-consuming process, which is particularly important today, the energy crisis, but its cost is too high, is not conducive to the promotion of electric vehicles, the Government Subsidies is important.

US Department of Energy will be in August of General Electric vehicle technology investments for a total of about 105 million financial subsidies. Currently, the US government holds $61 \%$ of the shares of the company, GM's total investment of over 500 billion dollars. Several countries have established grants and tax credits for the purchase of new electric cars depending on battery size. The US offers a federal income tax credit up to US\$7,500, and several states have additional incentives. The UK offers a Plug-in Car Grant up to a maximum of GB£5,000 (US\$7,600) beginning in January 2011. As of April 2010, 15 European Union member states provide tax incentives for electrically chargeable vehicles, which consist of tax reductions and exemptions, as well as of bonus payments for buyers of plug-ins and hybrid vehicles, This is conducive to strong government support for the promotion of electric vehicles, this approach eventually wealth for individuals and government savings.

\section{Energy Consumption Prediction Based on the Regression Equation}

Through the front discussion we find that it has enormous social and economic benefits to use electric vehicles. Today, considering the increasing depletion of fossil fuels, our main concern is how much resources it can save for the society. In the current energy use, fossil fuels accounted for the majority, so the energy consumption of electric vehicles is a large part of fossil energy obtained by consuming, for now, the popularity of 
electric cars to save energy may be limited, but as the US energy mix change, renewable resources and other clean energy use will greatly reduce the consumption of fossil fuels, we use the regression equation through the use of energy in recent years, years or even decades to predict the future of energy use, will be projected the popularity of electric cars can save fossil energy.

In the 21 st century is conducive to widespread use of electric vehicles on the environment must be replaced with some new energy, since 2001, the United States has in the development of renewable energy has invested nearly 100 billion dollars. The proportion of available energy in the United States in possession of most of the oil and gas wind, solar and other renewable resources are the proportion of very few.

In the following table for the 2001-2009 energy generating capacity around the world:

After analyzing the data in Table 6, We found that non-renewable resources, especially coal and possession of a larger proportion of serious environmental pollution, then the electric car to save fossil fuels are limited, to improve the fossil energy saving electric car rates, and solve the energy crisis And environmental issues we must vigorously develop clean energy, the table below reflects the 1991-2007 development of US energy.

By Figure 2, it's not hard to find the proportion of renewable resources continue to increase. According to the US Energy Information Administration predicts that, by 2030 about the US electricity supply will come from renewable energy. Then, the electric car to save fossil energy is very objective. The above data and analysis of electric vehicles shows how much energy savings in the group world-wide use of electric vehicles. Every five cars we believe there is an electric car, and every eight Individuals have a car. Now consider 2020, the widespread use of electric vehicles can save much fossil fuel. Figure 3 in the following shows the electric power structure in 2020:

Now the whole world within one year of the fuel consumption of cars and electric cars fossil energy consumption needs, now running $50 \mathrm{~km}$ per day per vehicle safety calculations, combined with calculation of 150 million cars in front of the fuel $2.24 \times$ $10^{3} \mathrm{~L}$, the same number of electric cars per year Requires $5.5 \times 10^{11} \mathrm{~kg}$ of coal to generate electricity.

Look at future electric cars, energy-saving situation, the development of world science and technology with the power structure to constantly adjust the ratio of share

Table 6. Energy generating capacity around the world (2001-2009).

\begin{tabular}{cccccccc}
\hline Description & 2009 & 2008 & 2007 & 2006 & 2005 & 2004 & 2003 \\
\hline Coal & 1755,904 & $1,985,801$ & $2,016,456$ & $1,990,511$ & $2,012,873$ & $1,978,301$ & $1,973,737$ \\
Petroleum & 38,938 & 46,243 & 65,739 & 64,166 & 122,225 & 121,145 & 119,406 \\
Natural Gas & 920,797 & 882,981 & 896,590 & 816,441 & 760,960 & 710,100 & 649,908 \\
Nuclear & 798,855 & 806,208 & 806,425 & 787,219 & 781,986 & 788,528 & 763,733 \\
Wind & 73,886 & 55,363 & 34,450 & 24,589 & 17,811 & 14,144 & 11,187 \\
Solar & 891 & 864 & 612 & 508 & & 550 & 575 \\
\hline
\end{tabular}




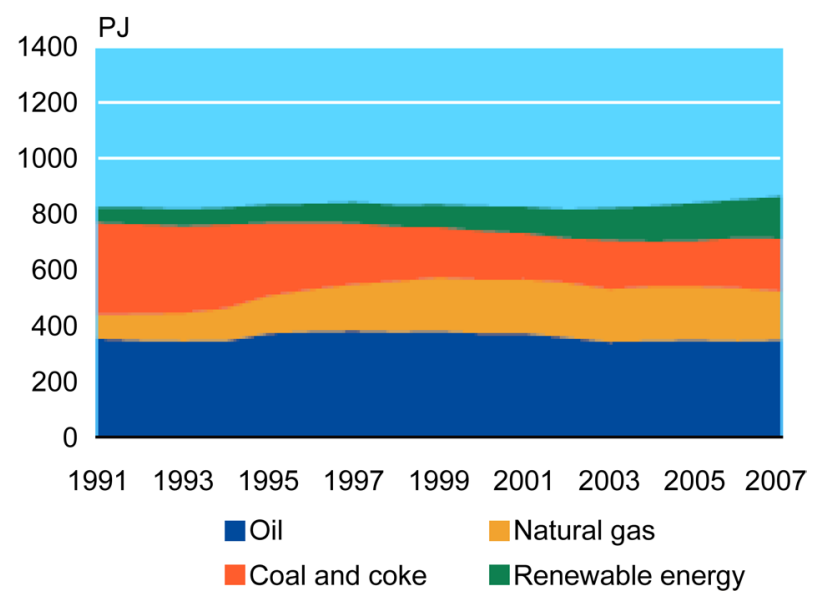

Figure 2. Renewable electric energy profile of US, 1991-2007.

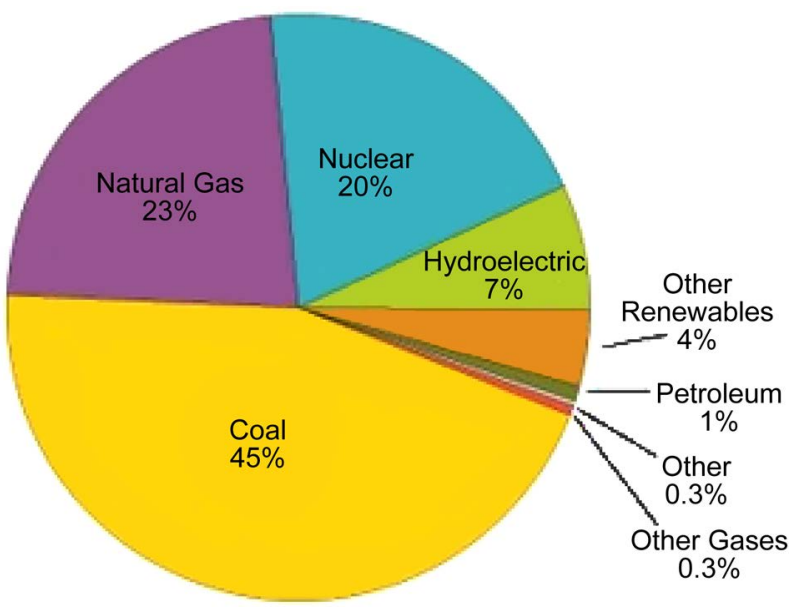

Figure 3. Renewable electric energy profile of US, 2020.

of renewable energy is increasing, and then produce the same power consumption of fossil fuels to the steady decline in the use of electric vehicles to bring even greater savings. Below is the world's power structure 2001-2009 the proportion of coal in power generation change.

This trend line through the predictable amount of energy a few years later, here we find the situation after three years and ten years.

Through Figure 4, we assume that the curve is consistent with the function again, set the function $y=a x+b$, and now we need to determine the equation by least squares method the coefficients, obtained by calculating the coefficient of function

$$
a=-0.008, \quad b=16.568 \text {. }
$$

The regression curve the coefficient is:

$$
y=-0.008 x+16.568 \text {, }
$$

in which, $x$ represents the years and $y$ represents the ratio of coal consumption.

Let $x=2013$ in Equation (5), it can be calculated that the ratio of coal consumption 


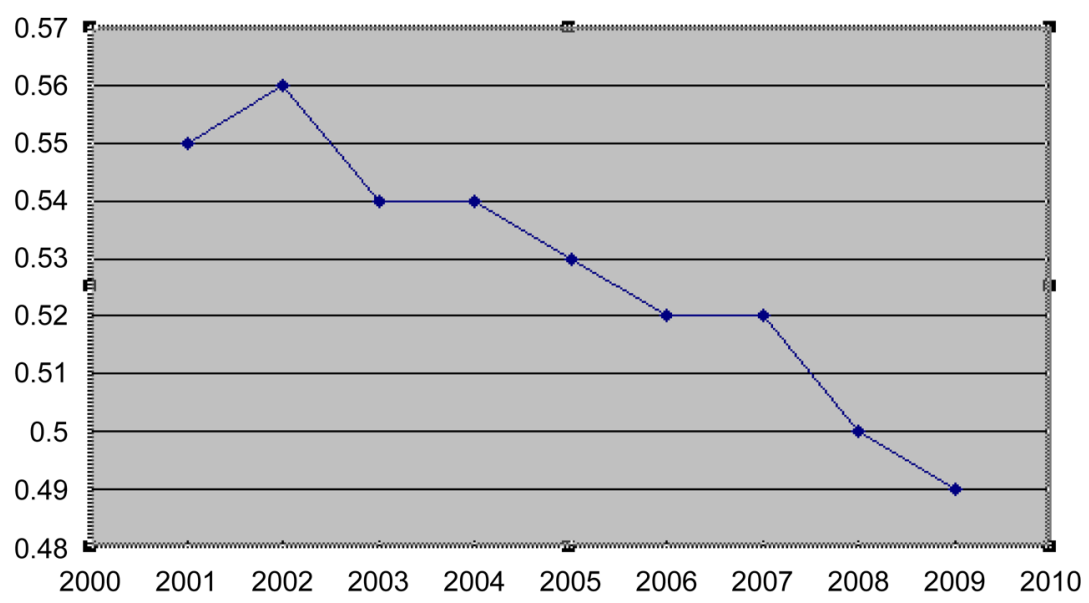

Figure 4. Proportion of coal in power generation, 2001-2009.

in 2013 is 0.464 , that is to say, the world-wide use of electric vehicles at the cost of coal is $5.3 \times 10^{11} \mathrm{~kg}$. Let $x=2020$ in Equation (5), it can be calculated that the ratio of coal consumption in 2020 was 0.388 , which tell us that the widely used in electric vehicles result in the world's consumption of coal is $4.4 \times 10^{11} \mathrm{~kg}$. So, we can see the development over time, annual consumption of coal for electric cars less and less, so the world more and more energy savings.

According to the US Energy Information Administration predicts that by 2030 about $40 \%$ of US electricity supply will come from renewable energy. Table 4 lists the 2030 renewable energy technologies, the potential contribution of US power. The study does not include offshore wind power. Including solar hot water use, but does not include the other solar thermal use (such as industrial process heat), nor does it include photovoltaic and wind generation of electricity storage.

By 2030 renewable energy technologies for American power potential contribution US National Research Council (NRC) issued in June 2009 forecast, non-hydro renewable energy supply capacity from the current $2.5 \%$ to $10 \%$ in 2020 and 2035, over $20 \%$. To achieve the $203520 \%$ renewable energy target, the US will need years to increase wind power capacity of $9500 \mathrm{MW}, 2008$ the year setting capacity of $8400 \mathrm{MW}$, is expected to 2035 between the increase in solar power generation capacity 70,000 MW and geothermal energy capacity of 13,000 MW, wind energy, solar light $\mathrm{V}$ and poly thermal solar power, geothermal and biomass conventional technology, there will be no technical obstacles to accelerate development.

Through the above analysis of these alternative to traditional power is possible and feasible. By that time the widespread use of electric cars will save more fossil fuels.

\section{Power Plant Planning Based on Multi-Objective Programming}

In the current, electric power structure in the United States including thermal power, natural gas, nuclear power and new energy. Figure 5 in the following shows the electric power consumption of the 2007 US energy situation.

Reasonable construction of various types of power plants now to meet the energy 
needs of electric vehicles. Now calculate how much energy, we assume that electric cars alternative vehicles, in the United States has 200 million cars, assuming that each and every tram running every $50 \mathrm{~km}$, then the total energy consumed within a year is $1.1 \times$ $10^{12} \mathrm{kwh}$ so it is necessary power station average power $1.26 \times 10^{8} \mathrm{Kw}$, we consider the type of power plant construction for the thermal power, hydropower, nuclear power and solar energy are four to consider solar and hydropower on the environment, no pollution, but construction costs are high, power plant construction cost is low but there is pollution, is now planning a reasonable amount of various power plants to consider both cost and minimize pollution, so this is a multi-objective programming problem. I combine a number of power plant types and standards, through multi-objective programming model to get a best arrangement to meet the minimum power in case it is necessary to consider the cost, but also consider the annual operating costs but also on the environment.

Table 7 shows the parameters of various types of power station.

Let the number of hydropower stations $x_{h}$, the number of nuclear power plants $x_{n}$, and the number of power plant for the $x_{p}$, the number of solar power plant $x_{s}$. Consider all the power to run for 20 years, we have established the objective function, that is, all the consumer in 20 years the minimum, the objective function is:

$$
\min Z=a_{1} f_{1}+20 a_{2} f_{2}+20 a_{3} f_{3} .
$$

s.t.,

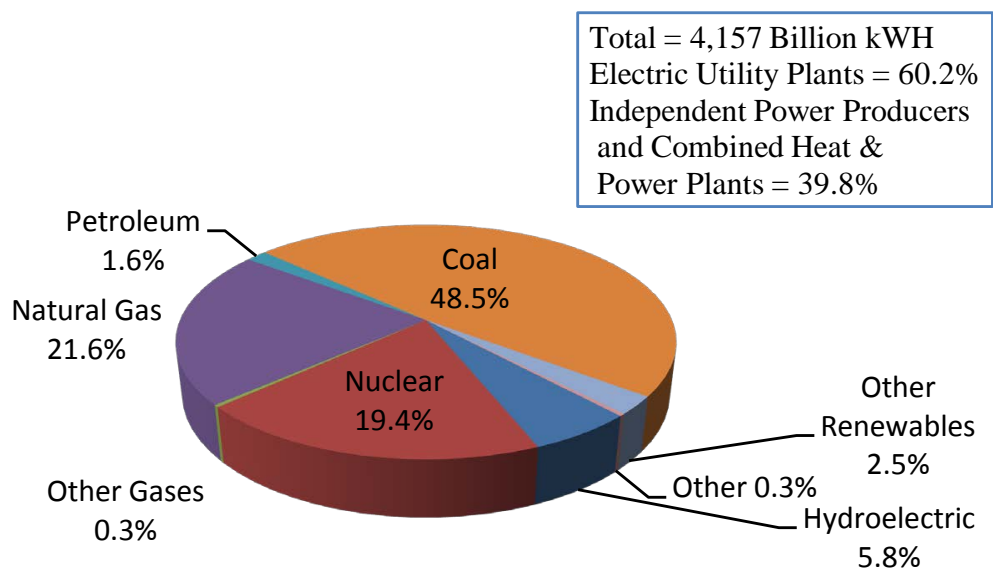

Figure 5. US Electric power industry net generation, 2007.

Table 7. The parameters of various types of power station.

\begin{tabular}{ccccc}
\hline $\begin{array}{c}\text { Power type treatment } \\
\text { (million) }\end{array}$ & $\begin{array}{c}\text { Power } \\
(\mathrm{Mw})\end{array}$ & $\begin{array}{c}\text { Cost } \\
\text { (million) }\end{array}$ & $\begin{array}{c}\text { Annual cost } \\
\text { (million) }\end{array}$ & $\begin{array}{c}\text { Pollution treatment } \\
\text { (million) }\end{array}$ \\
\hline Power plant & 0.35 & 100 & 2.3 & 17 \\
Nuclear power plant & 1000 & 50 & 3.16 & 0.13 \\
Solar power station & 0.006 & 10 & 0.23 & 0.005 \\
Hydropower & 30 & 1.4 & 1.2 & 0.007 \\
\hline
\end{tabular}




$$
\left\{\begin{array}{l}
f_{1}=2.3 x_{1}+50 x_{2}+10 x_{3}+1.4 x_{4}, \\
f_{2}=17 x_{1}+3.16 x_{2}+0.23_{3}+1.2 x_{4}, \\
f_{3}=0.35 x_{1}+0.13 x_{2}+0.005_{3}+0.007 x_{4},
\end{array}\right.
$$

in which $a_{1}, a_{2}, a_{3}$ is the weight coefficients.

In the United States, $\mathrm{NO}_{\mathrm{n}}$ and $\mathrm{SO}_{2}$ emissions usually related to the use of fossil fuel power plants, with generating capacity increases. Automobile exhaust levels of $\mathrm{NO}_{\mathrm{n}}$ and $\mathrm{SO}_{2}$ were also down, although since 1970, the total number of US car mileage increased by almost $150 \%$. These results are mainly due to more stringent vehicle engine and fuel standards.

Therefore, in view of national policy and international situation, should be possible to reduce pollution and take care of the interests of citizens, through the relevant literature and reality, the weight factor should be identified as $0.2,0.3,0.5$.

1) The power of all power stations and should meet certain requirements, that need is greater than the average charge over tram power constraint equations are listed as follows:

$$
10^{5} x_{1}+10^{6} x_{2}+6 x_{3}+3 \times 10^{4} x_{4}>1.26 \times 10^{8} .
$$

2) For the purpose of meeting the power constraint equations were considered under the conditions of cost, annual operating costs, pollution treatment for the constraint equations are listed:

$$
\left\{\begin{array}{l}
2.3 x_{1}+50 x_{2}+10 x_{3}+1.4 x_{4}>\min f_{1}, \\
17 x_{1}+3.16 x_{2}+0.23_{3}+1.2 x_{4}>\min f_{2}, \\
0.35 x_{1}+0.13 x_{2}+0.005_{3}+0.007 x_{4}>\min f_{3},
\end{array}\right.
$$

Using integer optimization by Lingo, we get

$$
x_{h}=5, x_{n}=36, x_{p}=0, x_{s}=80 .
$$

\section{Conclusions}

In the previous study, the mathematical model of the electric car on the environmental, social and economic impact, it can really improve the environment and ease the energy crisis, but in the course of the study do exist, we know that the issue should not be neglected, the number of ordinary battery charge and discharge times of only 300 to 400, even if the good performance of the battery charge and discharge times, but also 700 to 900 times, 200 times per year calculated discharge, a battery life of up to 4 years, compared with the life of the fuel cars than too short. In addition, different types of batteries have their own in terms of performance strengths and weaknesses, for example, lead-acid batteries, low cost, abundant raw materials and easy to recycle, but the short driving range, speed and power differential short life. Nickel-cadmium batteries to accelerate enough power, longer life expectancy. But its high cost, poor recyclability. Sodium sulfur battery high specific energy can provide a longer driving range. But it requires more demanding work environment. 
And electric cars are expensive, complicated mainly battery technology, the cost is too high, There is also thanks to a series of new materials, new technologies, resulting in high cost of electric vehicles. The price of batteries for electric vehicles is about 100 US dollars $/ \mathrm{kW} \cdot \mathrm{h}$, and even some up to 350 dollars $/ \mathrm{kW} \cdot \mathrm{h}$, the cost is too high, users bear.

Most noteworthy is its indirect pollution is serious, previously discussed, although no emission pollution electric vehicle itself, but the indirect pollution cannot be ignored. Lead-acid batteries such as lead, from the mining, smelting to the production of sewage will pollute the environment. Another example is the electrical energy, a large part from thermal power, coal, fuel can also cause air pollution.

Therefore, the development of electric vehicles in the future these issues should be considered in the future should focus on considering the development of hybrid vehicles, battery performance due to the severe constraints, to pure battery electric vehicles industrialization process difficult, so the internal combustion engine vehicles into hybrid vehicles and the transition between the products of electric vehicles, both full advantage of existing internal combustion engine technology, but also maximize the advantages of motor-driven pollution. Existing internal combustion engine hybrid electric vehicle energy storage components and certain advanced control system through the combination can significantly reduce fuel consumption, reduce emissions, while technology is mature, the price is cheap.

For now, the traditional internal combustion engine vehicles are still dominant in today's world, but the development of clean and pollution-free electric vehicles is a general trend, but also an inevitable choice for countries in the world. At present, the commercialization of electric vehicles in operation, in terms of technology or product development from the market, are still facing many problems to be solved, which require strong government support. For example, to speed up the development of relevant technical standards, introduction of energy saving, environmentally friendly car tax relief and subsidies, to provide the infrastructure to facilitate the conditions.

In a large part of the article with the electric vehicle-related energy problems, and now there are serious irrational world energy, fossil energy consumption is too large, so that not only caused the depletion of energy has also brought serious environmental problems, so changing the energy structure Opened without delay, the Government should increase efforts to develop new energy sources, improve the proportion of renewable resources, the possession, so that electric car in the promotion of less fossil resources consumption, less pollution generated, so the electric car is to solve the energy problem, A way of environmental problems, the Government should increase support for the development and promotion of electric vehicles.

\section{Acknowledgements}

This research was supported by the National Natural Science Foundation of China (No. 11601036), the Natural Science Foundation of Shandong (No. ZR2014GQ005) and the Natural Science Foundation of Binzhou University (No. 2016Y14). 


\section{References}

[1] (2010) Electric Cars: Highly Charged Motoring. The Economist, 22-26.

[2] Wikipedia (2016) Energy in the United States. https://en.wikipedia.org/wiki/Energy in the United States

[3] Wikipedia (2016) Electric Car. https://en.wikipedia.org/wiki/Electric car

[4] Wikipedia (2013) List of Electric Cars Currently Available: Difference between Revisions. https://en.wikipedia.org/w/index.php?diff=prev\&oldid $=588558324 \&$ title $=$ List of electric $\mathrm{c}$ ars currently available

\section{Submit or recommend next manuscript to SCIRP and we will provide best service} for you:

Accepting pre-submission inquiries through Email, Facebook, LinkedIn, Twitter, etc.

A wide selection of journals (inclusive of 9 subjects, more than 200 journals)

Providing 24-hour high-quality service

User-friendly online submission system

Fair and swift peer-review system

Efficient typesetting and proofreading procedure

Display of the result of downloads and visits, as well as the number of cited articles

Maximum dissemination of your research work

Submit your manuscript at: http://papersubmission.scirp.org/

Or contact jamp@scirp.org 